\section{Race and the Precipitin Test}

Conclusions of some considerable interest to physical anthropologists and students of questions of race are drawn by Prof. V. Suk of the Anthropological Department of Masaryk University, Brno, from the results of work on racial immunity on the basis of the precipitin test (Act. Soc. Sci. Nat. Moraviae, 8, fasc. 4, sig. 5). The author's objective was the differentiation by biological experiments between micro- or meso-diacritical races and the fully established pan- or macro-diacritical races. The material for sera and anti-sera was derived from Eskimo, Kalmuk, Nordic (Slovakia and Bohemia), Baltic, Alpine (Czech), Gipsies and Jews. Four hundred and five experiments, with eight dilutions, thus giving more than three thousand precipitations, were made. Without going into details, it may be said that the highest degree of reaction was given by the compared Eskimo-Kalmuk groups, hence regarded as pan-diacritical and fully established races, and the lowest by Jew-Nordic. On the basis of his results, Prof. Suk enters into a discussion of racial types at some length, taking into account, in particular, the work of Keith, Parsons and of Ruggles Gates on Amerindian crosses in Canada. He offers the opinion that the various groups among Europeans are not fully established races, but inconstant variations in process of making, while the modern racial history of Europe shows no visible trend to develop types such as 'Nordic', 'Dinaric', 'Alpine', etc., into true races, but rather to form new groups, according to geographical distribution, such as 'English', 'North American', 'German', 'Italian', and so forth. It is regarded as doubtful if such groups will ever attain the status of true races. The present investigation seems to show that all these types are of one stock and that Europeans in general are a very old variation of the species Homo.

\section{Walnut Production in England}

Some account of the steps that are being taken to promote and improve walnut production in England is given by $\mathbf{J}$. B. Hammond in the annual report of the East Malling Research Station for 1932. As the outcome of a large and successful walnut survey and competition in 1929, propagation studies have been started with carefully selected trees from different parts of England. Material has also been collected from other countries, notably France and California, including scions from trees known to produce the 'burred' type of wood valuable for cabinet making. Up to the present, grafting has only proved successful if carried out under glass, a frame with bottom heat of $60^{\circ}-70^{\circ} \mathrm{F}$. being used, but the plants can be hardened off after three weeks and, if grafted in June, are ready to be planted out by the end of August. Nuts may be produced after 3-5 years. A good nut should contain at least 50 per cent oil, for if the value is lower the water content is correspondingly increased, which results in impaired flavour and a tendency to shrivel during storage. The methods of storage are of the first importance. Cold storage at $38^{\circ} \mathrm{F}$. combined with
90 per cent humidity prove entirely satisfactory. If, however, a higher temperature is maintained, a fungicide is necessary. Common salt, preferably mixed with coco-nut fibre or sodium phosphate to take up the moisture absorbed from the atmosphere by the salt, may be safely used, and nuts placed in earthenware crocks in alternate layers with this salt-mixture keep in good condition until the following spring.

\section{Report of the Empire Marketing Board}

Ir is encouraging to learn from the Report of the Empire Marketing Board for 1932-33 (H.M. Station. ery Office, $1 s$.$) , that in spite of the economic depres-$ sion during this period, twenty-four new records in the shipment of Empire products to Great Britain have been set up. Among the outstanding examples where the increase in the import has been nearly or even more than doubled are Australian eggs, Canadian tobacco, British West Indian bananas and New Zealand pears. Although a reduced vote has precluded any extension of its research programme, the Board has in general been able to maintain its grants, and a full account of the work in hand at the various institutes benefited is given in the report. Progress continues in the planning of joint programmes of research, and suggestions of special problems requiring investigations have been received from India and the Colonial Advisory Council of Agriculture and Animal Health during the past year. The market intelligence services have been continued and far-reaching developments in this direction are anticipated since the inauguration of an Empire broadcasting service at the invitation of the B.B.C. Considerable success has attended the Board's publicity activities, and both the number of films available and the public demand for them has been trebled during the year under review.

\section{Exploration in the Gobi Desert}

Attentron may be directed to an article by Dr. R. C. Andrews on "Exploration in the Gobi Desert" (National Geographic Magazine, June 1933) which recounts the work of the Central Asiatic Expedition under his leadership in various years between 1922 and 1930. The importance of the article lies in the fine pictorial record of the Gobi Desert and Inner Mongolia. The pictures illustrate the topography and anthropology but are of interest mainly in their relation to the extraordinary palæontological discoveries, including a number of early mammals as well as the eggs of the dinosaur (see also p. 81 of this issue). Many of the pictures are colour photographs.

\section{The Antarctic Continent}

IN a lecture to the Royal Institution delivered on March 3 on the new polar province in the Antarctic, Sir Douglas Mawson, after pointing out the extent of the antarctic that has been placed under the administration of the Australian Commonwealth, outlined the most recent ideas with regard to the 
antarctic continent. His own discoveries in the Australian province confirm the belief, previously held, of the continuity of the southern land mass. The rocks are pre-Cambrian and early Palæozoic in the main but on the Pacific side there is a large tract of Permian to Triassic beds lying almost horizontally on the older formations. South of the American continent, however, a region of different tectonic structure is found with folded beds of secondary and tertiary age. This region, known generally as Graham Land, appears to be an island chain bound together and to the continent by a permanent shelf-ice sheet of great thickness. Sir Douglas Mawson pointed to the possibility of the Ross Barrier at the head of the Ross Sea extending unbroken to the barrier at the head of the Weddell Sea. If this is the case, the archipelago of Graham Land is not part of the antarctic continent but is joined to it by a vast sheet of floating shelf-ice. The lecture has recently been made available in pamphlet form.

\section{Treatment of Pernicious Anæmia}

THE treatment of pernicious anæmia by a diet containing large amounts of liver or by the oral administration of an extract of liver or of desiccated stomach tissue is now the standard treatment for this disease. For patients who are severely ill and cannot tolerate oral administration, the intramuscular or intravenous injection of a potent extract of liver may be a life-saving measure; moreover, by the parenteral route, smaller doses are required and the response of the blood is quicker. The British Drug Houses, Ltd., London, N.1, are now issuing an extract of liver for intramuscular injection. Each cubic centimetre contains the anti-anæemic principles of $50 \mathrm{gm}$. of fresh liver, whilst its depressor effect does not exceed that of a 0.0005 per cent solution of histamine acid phosphate when introduced by the intravenous route into an etherised ca.t. In addition to Liver Extract B.D.H., and Liquid Liver Extract B.D.H., preparations for oral administration in the treatment of pernicious anæmia, the British Drug Houses also issue the product 'Livogen', which is a highly concentrated liquid preparation containing in one fluid ounce the whole of the hæmotopoietic principles (including vitamin B) of four ounces of fresh liver. It contains additional vitamin $\mathrm{B}$ extract equivalent to one ounce of fresh yeast in each fluid ounce, together with five grains of hæmoglobin. For the specific anæmias, in which massive doses of iron are indicated, iron ammonium citrate may be dispensed with Livogen, the two products being in every way compatible. Livogen is recommended for use in convalescence from severe illness as well as in both primary and secondary anæmias.

\section{Odour of Vulcanised Rubber}

As the rather unpleasant odour of vulcanised rubber limits its applications, the Rubber Growers' Association has instituted an investigation into its causes and prevention (Bull. Rubber Growers' Association, May, 1933). When rubber goods were made from inferior grades of wild rubber, their smell was due to putrefactive changes, but in these days of plantation rubber, the trouble arises mainly from the accelerator employed, although macintoshes and other proofed goods owe their smell to the low-grade petroleum and coal-tar naphtha products that are used as diluents when the rubber is manufactured. Vulcanised goods can often be temporarily freed from odour by steaming them, but permanent freedom can only be secured by removing the substances that give rise to odour, whether they be constituents of the raw rubber or added to it in the course of manufacture. The smell due to accelerators may be of the 'sulphide' or of the 'amino' type, according as they contain sulphur or amino-nitrogen. So far, no good accelerator that is free from these constituents has been found, but Messrs. H. P. Stevens and E. J. Parry, the chemists in charge of the investigation, have discovered that the presence of zinc carbonate in the compounding mixture reduces the smell to a minimum. The slight 'amino' smell characteristic of the unvulcanised plantation rubber has been traced by them to the proteins, and not to the resins, present in the raw material; and it can be practically eliminated if the latex is purified by such methods as digestion with dilute caustic, centrifuging, creaming, ultra-filtration, or dialysis. When the problem has been definitely solved, it will be possible to use vulcanised rubber for lining foodcontainers and brewers' vats, and in the preparation or packing of foodstuffs in general.

\section{Heating of Domestic Pendant Lamp Fittings}

The usefulness of scientific research on everyday domestic devices is shown by a paper read to the Institution of Electrical Engineers by P. D. Morgan, H. G. Taylor and W. Lethersich on April 20. The problem they had to solve was to find the best way of keeping the heating of lamp fittings and their connecting flexible wires at such a low value that the rubber insulation would not deteriorate. This deterioration takes the form of hardening and making brittle the rubber surrounding the wire. In this case a slight disturbance may cause it to crack off and expose the bare conductor. This may lead to a short-circuit and so possibly to igniting the 'flex'. It would be a rare occurrence but it would be advisable to prevent it. The deterioration of the rubber is due to its oxidisation, which is accelerated by heat. The introduction of gas-filled lamps has appreciably raised the temperature of the flexible wire connected to the holder and thus the problem has become more urgent.

The solution adopted in the United States is to use flexible cords capable of withstanding higher working temperatures than the usual standard rise of $23 \cdot 4^{\circ} \mathrm{C}$. at a distance of $\frac{5}{8} \mathrm{in}$. from the terminal. A lampholder and its connecting leads receive heat by conduction through the cap from the hot gas in the lainp and dissipate it by radiation and convection. It is necessary to make the heat conducted through the cap of the lamp smaller and facilitate the 